\title{
DIELECTRIC DISPERSION IN 1,2-DIAMINOPROPANE- DIMETHYLAMINOETHANOL MIXTURES AS A FUNCTION OF COMPOSITION AND TEMPERATURE
}

\author{
P. Undre and P. W. Khirade \\ Microwave Research Laboratory, Department of Physics, Dr. Babasaheb Ambedkar Marathwada University, \\ Aurangabad-431004, India \\ E-mail: prabhakarundre@yahoo.co.in
}

Received 23 April 2011; revised 9 November 2011; accepted 1 December 2011

\begin{abstract}
The dielectric dispersion $\varepsilon^{\prime}$ and dielectric loss $\varepsilon^{\prime \prime}$ of binary mixture of 1,2-diaminopropane-dimethylaminoethanol were measured by employing the time domain reflectometry technique over a frequency range from $10 \mathrm{MHz}$ to $20 \mathrm{GHz}$ at $288,298,308$, and $318 \mathrm{~K}$ temperatures. The accuracy in the measurement of the $\varepsilon^{\prime}$ and $\varepsilon^{\prime \prime}$ values obtained from this technique is within $\pm 5 \%$. To evaluate various dielectric parameters, the frequency dependents complex permittivity $\left(\varepsilon^{*}(\omega)=\varepsilon^{\prime}-\mathrm{i} \varepsilon^{\prime}\right)$ data, viz., static permittivity $\varepsilon_{0}$, relaxation time $\tau$, and permittivity at high frequency $\varepsilon_{\infty}$ were fitted by the nonlinear least-squares fit method to Debye expression. Temperature dependent $\varepsilon_{0}, \tau$, Kirkwood correlation factor $g$, free energy of activation $\Delta G$, and enthalpy of activation $\Delta H$ have been determined and discussed in terms of the effect of $-\mathrm{NH}_{2}$ and $-\mathrm{CH}_{3}$ side-group on molecular dynamics and intermolecular hydrogen bonds. The dielectric behaviour of 1,2-diaminopropane and dimethylaminoethanol liquid molecules and their conformations as well as molecular dynamics of the system can be explored only by comparing the dielectric data of the mixture system with the dielectric data of the individual molecules and their dynamics.
\end{abstract}

Keywords: dielectric dispersion, dielectric loss, excess parameters, Kirkwood correlation factor, thermodynamic parameters

PACS: 77.22.Ch, 77.22.Gm, 77.84.Nh

\section{Introduction}

Microwave energy has been directly applied in many fields, especially in scientific research such as communication, microwave-assisted chemistry and in food industry $[1,2]$. A successful application of microwaves is directly associated with the dielectric properties of the materials. An accurate measurement and working knowledge of these properties are key factors in better understanding the interaction of microwaves with the materials. Dielectric relaxation spectroscopy, for instance, is a powerful tool for examining the underlying physics of solvent systems and for exploring the molecular dynamics of liquids, which is characterized by inter- and intra-molecular structures that vary rapidly with time.
Studies on the relaxation properties of the mixture of solvents have provided some interesting insights into the volumes implicated by the Debye expression and the nature of the mixing process. If the solvents are chemically similar and mix well at the molecular level, then the mixture will often exhibit a single relaxation time at an average position, which reflects the molar ratios of two components. However, if the solvents do not mix well at the molecular level, then two distinct relaxation times are observed and they do not differ greatly from those of pure solvents.

The knowledge of frequency dependent dielectric properties of solvent systems is important both in fundamental studies of solvent structure and dynamics and in practical application of microwave heating processes [1]. At a fundamental level, the 
frequency dependent dielectric behaviour of solvent mixtures provides information on molecular interactions and mechanism of molecular processes. The dielectric relaxation behaviour of mixtures of polar molecules under varying conditions of compositions is very important as it helps in obtaining information about relaxation processes in mixtures.

Becker et al. [3] carried out a systematic study of dielectric relaxation of monohydric alcohol with dihydric alcohols (diols) solutions at $293 \mathrm{~K}$ over the frequency range of $5 \mathrm{MHz}$ to $72 \mathrm{GHz}$ using the lumped circuit, coaxial and waveguide method. The principal component, which is related to the dynamics of self- and/or hetro-association, is discussed with respect to steric conditions. In mixtures of monohydric (1-butanol) with longer chain 1,2diols, the principal relaxation time passes through a minimum on increasing the dihydroxy content. In mixtures of tert-butanol (which has a weaker selfassociation tendency) with longer chain $1, n$-diols, on the other hand, it passes through a maximum. With regard to the principal relaxation strength, longer chain 1,2-diols tend to resemble monohydric alcohols of full diol chain length while 1,n-diol tends to resemble monohydric alcohol of half the diol chain length.

Sengwa et al. [4] studied the dielectric relaxation in propylene glycol-poly propylene glycol mixtures over three concentrations in the frequency range $10 \mathrm{MHz}$ to $4 \mathrm{GHz}$ at $298 \mathrm{~K}$ using Time Domain Reflectometry (TDR). The effective Dielectric relaxation is shown to depend exponentially on the number density of dipoles or molecules. Puranik et al. [5] studied the dielectric properties of ethanol and ethylene glycol using TDR techniques in the frequency range of $10 \mathrm{MHz}$ to $10 \mathrm{GHz}$ over the temperature range $243-313 \mathrm{~K}$. The activation energies of both systems are compared.

Hanna et al. [6] carried out a dielectric relaxation study of monohydroxy-dihydroxy alcohols binary and monohydroxyl-diol-diol ternary mixtures at $293 \mathrm{~K}$ over the frequency range from $10 \mathrm{MHz}$ to $10 \mathrm{GHz}$ using the TDR technique. An apparent dipole moment term and the effective relaxation time of the main dispersion region are given as a function of the number density of dipoles.

To compare the influence of different polar groups in the relaxation mechanism, we have considered it interesting to perform an analogous treat- ment such as that carried out for binary mixture of primary alcohols-diol, dio-diol. For this reason, dielectric dispersion study in 1,2-diaminopropane (DP) with dimethylaminoethanol (DMAE) mixtures over the frequency range of $10 \mathrm{MHz}$ to $20 \mathrm{GHz}$ has been carried out using pico-second TDR. The binary system of DP-DMAE has been selected to understand the effect of amino and methyl sidegroup on the dielectric parameters, where the significance is based upon the tetrahedric nature of the $-\mathrm{NH}_{2}$ group. This extreme is of decisive relevance for the process of chemical synthesis, the behaviour of amino acids and proteins in biochemical models related to biogenic amines which contribute to the mechanism of electrical conduction in the nervous system, especially in nurotransmission.

This binary system of DP and DMAE is of interest because of two functional groups in both components with one common $-\mathrm{NH}_{2}$ group. The four sites available for $\mathrm{H}$-bonding in a DP molecule promote a set of transient cross links between neighbouring molecules. In such a case, relevant transient structures such as branched associated species and/or chains are formed. In addition, many conformations can be generated for each molecule by the rotation of $\mathrm{CH}_{2} \mathrm{NH}_{2}$ group around the $\mathrm{C}-\mathrm{C}$ axis with respect to $\mathrm{H}_{2} \mathrm{~N}-\mathrm{CH}-\mathrm{CH}_{3}$ group. DMAE is a hydroxylamine, tertiary amine, versatile and polyfunctional molecule that combines the characteristics of amines and alcohols and is capable of undergoing reactions typical of both alcohols and amines. Competition for $\mathrm{H}$-bond site governs the nature of short-range order around molecules of both components of the solvent mixture. For the hydroxyamines, this is the dominant feature. The molecules of DMAE exist in intermolecular hydrogen bonded form with the rotation of $\mathrm{CH}_{2} \mathrm{~N}-$ $\left(\mathrm{CH}_{3}\right)_{2}$ group around $\mathrm{C}-\mathrm{O}$ bond in dynamic equilibrium. The dielectric study of the binary system of these DP and DMAE molecules will give information about interaction between $\mathrm{OH}-\mathrm{NH}_{2}$ and $\mathrm{NH}_{2}-\mathrm{NH}_{2}$ group thereby forming different types of structures.

Due to good solubility of DP in DMAE, these molecules may form a variety of clusters due to inter- and intra-molecular hydrogen bonds, depending on the molecular geometry of individual molecules, and hence, it is interesting to investigate the variation in the shapes of the dielectric relaxation curves of the DP-DMAE system with concentration. 
The concentration dependence of the shape of the relaxation curves and various dielectric parameters of the DP-DMAE mixture are compared with those of the monomeric, dimeric, trimeric and polymeric molecules in the DP-DMAE solution, to obtain some insight into the possible relaxation behaviour of the DP and DMAE molecules in their mixtures. The relaxation curves are treated assuming one relaxation process, and their shapes are discussed based on the cooperativity of DP and DMAE molecules.

The dipole moment value of DP molecules is slightly larger than the dipole moment values of DMAE in the gas phase. The values of static permittivity $\varepsilon_{0}$, relaxation time $\tau$, activation enthalpy $\Delta H$, and Gibbs free energy of activation $\Delta G$ for DP are larger than those for DMAE. The difference in permittivity values of pure DP and DMAE are due to difference pattern of alignment of dipoles in liquid.

\section{Experimental set-up}

\subsection{Chemicals}

The chemicals used in the present work, 1,2-diaminopropane and dimethylaminoethanol, were of spectroscopic grade and were obtained from ACROS ORGANICS, New Jersey, USA, and Kemphasol, Bombay, respectively, commercially with 99\% purity and were used without further purification. The solutions were prepared at different volume percentage of DP in DMAE in the step of $10 \%$ at room temperature. The concentrations were prepared for $5 \mathrm{ml}$ solution at room temperature assuming ideal mixing behaviour, within $0.02 \%$ error limit.

\subsection{TDR set-up and data acquisition}

The Hewlett Packard HP54750A sampling oscilloscope with HP54754A TDR plug-in module has been used. After observing TDR response for a sample under study, the time window was kept to $5 \mathrm{~ns}$. By observing TDR response for a sample under study, the SMA sample cell with $1.35 \mathrm{~mm}$ effective pin length was used. The sample cell holds the liquid under consideration. The physical dimensions of the cell are very important, so one must be careful while designing the sample cell. The impedance of the cell should be matched with the coaxial transmission line to which the cell is connected. If there is impedance mismatch, then unwanted reflections may disturb the wave thereby causing some errors in the measurements. The proper design of the cell includes the inner conductor and outer conductor diameters. The length of the inner conductor is called the 'pin length' of the cell and is a very important factor in analysis. The sample length must be enough to avoid unwanted reflections.

In the total reflection method, the sample length must be long enough to produce an adequate difference signal but short enough to keep less complication of resonance effects at frequencies above the range of interest.

The characteristic impedance of a coaxial line is given by

$$
Z=\frac{138.2}{\sqrt{\varepsilon}} \log _{10} \frac{b}{a}
$$

This impedance for our transmission line is frequently $50 \Omega$. Here, $a$ is the diameter of inner conductor, $b$ is the inner diameter of outer conductor, and $\varepsilon$ is the relative permittivity of the dielectric between the conductors. Using Teflon and air and taking appropriate $a, b$, a cell can be designed to have a matching impedance of $Z=50 \Omega$ (for air $\varepsilon=1$ and for Teflon $\varepsilon=2.2$ ). The sample cell consists of standard military applications (SMA) coaxial connector with matched impedance with $3.5 \mathrm{~mm}$ inner diameter of outer conductor. The inner conductor of SMA connector itself is considered as inner conductor' and hex-nut is treated as an outer conductor. Since these SMA connectors have already been designed for precise $50 \Omega$ impedance, a special design, when used with high frequency, is not required. The physical length of inner conductor can be changed. When the cell is filled with sample above the physical length of inner conductor, the fringing effect takes place $[7,8]$. Due to the fringing field, the effective pin length [9] will not be equal to the physical pin length. The effective electrical pin length will be greater than the physical pin length. The accurate determination of the effective pin length $d$ is very important for the accurate evaluation of dielectric parameters. It is found that for SMA type cell, the effective pin length [9] is greater than the actual physical length by $0.1-0.2 \mathrm{~mm}$. 
To reduce noise, the time dependent response curve was averaged for 64 times and then stored in TDR oscilloscope memory with 1024 points per waveform. First, the response waveform for an empty cell is acquired and stored in memory and then, secondly, the response waveform for a sample is acquired and stored in other memory. The empty cell waveform is used as a reference waveform. Both response waveforms are the reflected waveforms from the sample cell with the open termination transmission line.

The data acquisition is carried out for 11 concentrations at $288,298,308$, and $318 \mathrm{~K}$. The temperature of a sample was maintained at a desired value, within accuracy limit of $\pm 1 \mathrm{~K}$, by circulating constant temperature water through heat insulating jacket surrounding the sample cell.

At each time the response waveforms without a sample and with a sample were recorded. The time dependent response waveform without a sample is referred to as $R_{1}(t)$ and with a sample as $R_{\mathrm{x}}(t)$.

\subsection{Data analysis}

The time dependent data were processed to obtain complex reflection coefficient spectra $\rho^{*}(\omega)$ over the frequency range from $10 \mathrm{MHz}$ to $10 \mathrm{GHz}$ using Fourier transformation as $[10,11]$

$$
\rho^{*}(\omega)=\frac{c}{\mathrm{i} \omega d} \frac{p(\omega)}{q(\omega)},
$$

where $p(\omega)$ and $q(\omega)$ are Fourier transformations of $R_{1}(t)-R_{\mathrm{x}}(t)$ and $R_{1}(t)+R_{\mathrm{x}}(t)$, respectively, $c$ is the velocity of light, $\omega$ is angular frequency, $d$ is effective pin length, and $\mathrm{i}=\sqrt{-}-1$.

The complex permittivity spectra $\varepsilon^{*}(\omega)$ [12] were obtained from reflection coefficient spectra $\rho^{*}(\omega)$ by applying the bilinear calibration method [13].

The complex permittivity spectra measured using TDR are fitted by the nonlinear least-squares fit method to the Havriliak-Negami expression [14] to obtain various dielectric parameters. The accuracy in the measurement of dielectric dispersion $\varepsilon^{\prime}$ and dielectric loss $\varepsilon^{\prime \prime}$ values obtained from this technique is within $\pm 5 \%$.

$$
\varepsilon^{*}(\omega)=\varepsilon_{\infty}+\frac{\varepsilon_{0}-\varepsilon_{\infty}}{\left[1+(\mathrm{i} \omega \tau)^{(1-\alpha)}\right]^{\beta}},
$$

where $\varepsilon^{*}(\omega)$ is the complex permittivity at an angular frequency $\omega, \varepsilon_{\infty}$ is the permittivity at high frequency, $\varepsilon_{0}$ is the static permittivity, $\tau$ is the relaxation time of the system, $\alpha$ is the shape parameter representing symmetrical distribution of relaxation time, and $\beta$ is the shape parameter of an asymmetric relaxation curve.

Equation (3) includes Cole-Cole $(\beta=1)$ [15], Davidson-Cole $(\alpha=0)$ [16], and Debye ( $\alpha=0$, $\beta=1$ ) [17] relaxation models. The dielectric model for fitting dielectric parameters suitable for present system is the Debye dispersion model.

\section{Results and discussion}

Frequency dependence curves for the dielectric dispersion $\varepsilon^{\prime}$ and absorption $\varepsilon^{\prime \prime}$ of DP-DMAE with varying volume fraction of DMAE at $298 \mathrm{~K}$ are depicted in Figs. 1 and 2, respectively. In the case of DP-DMAE mixtures, there is a considerable possibility of modifications in these homomolecular clusters due to molecular interactions between the DP and DMAE molecules. Apart from the complexities in the DP-DMAE mixtures, the observed dielectric dispersion behaviour is a simple Debyetype for all the concentrations studied, and this is also the case for the individual molecules.

Both $\varepsilon^{\prime}$ (Fig. 1) and $\varepsilon^{\prime \prime}$ (Fig. 2) increase with increasing volume percentage of DMAE in the binary mixture DP-DMAE at the low-frequency end and decrease at the high-frequency end. The frequency at which the loss factor is a maximum,

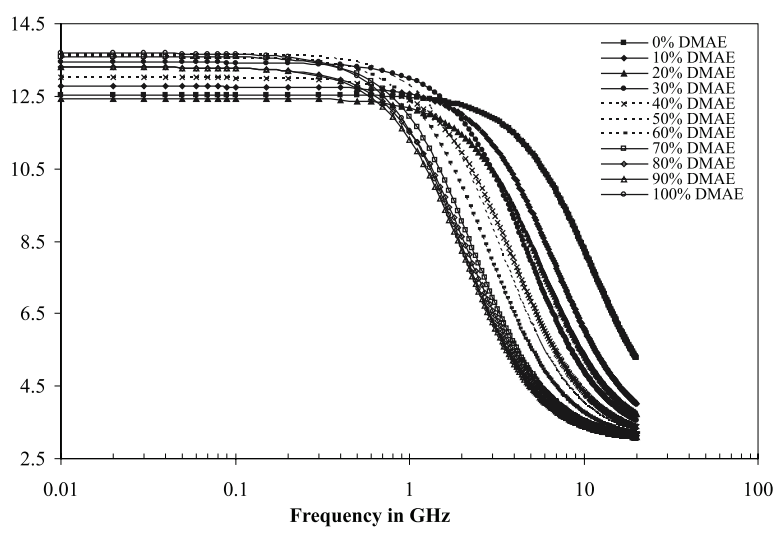

Fig. 1. Frequency dependent dielectric dispersion $\varepsilon^{\prime}$ curves for 1,2-diaminopropane, dimethylaminoethanol and their mixtures at $298 \mathrm{~K}$. 
$f_{\max }\left(\tau=1 /\left(2 \pi f_{\max }\right)\right)$ shifts to higher values with decreasing the volume percentage of DMAE in the mixture, corresponding to their individual relaxation times, because the individual molecular values

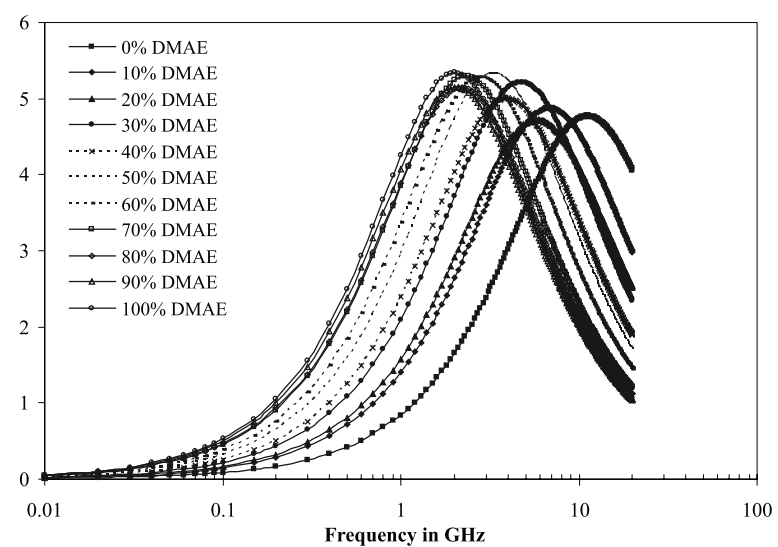

Fig. 2. Frequency dependent dielectric loss (absorption) $\varepsilon^{\prime \prime}$ curves for 1,2- diaminopropane, dimethylaminoethanol and their mixtures at $298 \mathrm{~K}$. are sufficiently different (i. e. 79.21 and 14.23 ps) to allow their resolution in practice. However, in a mixture of two associated liquids it seems that the individual principal relaxation processes of the components coalesce, and hence the mixture exhibits a single relaxation time. Earlier, Kumar et al. [18] observed Debye-type behaviour in amines (aliphatic/aromatic)-alcohol mixtures, despite large differences in the values of individual molecule relaxation times.

The values of the dielectric parameters $\varepsilon_{0}$ and $\tau$ obtained from Eq. (3) for DP, DMAE and DPDMAE with the volume fraction of DMAE at four different temperatures are recorded in Table 1. From Table 1 it can be observed that static permittivity systematically increases with increase in volume fraction of DMAE in DP. The same type of change in permittivity values has been observed at four temperatures under study.

The $\tau$ values gradually increase with increase in volume fraction of DMAE in DP. With increase in

Table 1. Temperature dependent dielectric parameters for binary mixture of dimethylaminoethanol-1,2-diaminopropane. Number in parenthesis represents error, e. g. 13.06 (02) means $13.06 \pm 0.02 \mathrm{X}_{\mathrm{DMAE}}$ volume fraction of dimethylaminoethanol.

\begin{tabular}{|c|c|c|c|c|}
\hline \multirow{2}{*}{$\mathrm{X}_{\mathrm{DMAE}}$} & \multicolumn{2}{|c|}{$288 \mathrm{~K}$} & \multicolumn{2}{|c|}{$298 \mathrm{~K}$} \\
\hline & $\varepsilon_{0}$ & $\tau, \mathrm{ps}$ & $\varepsilon_{0}$ & $\tau, \mathrm{ps}$ \\
\hline 0 & $13.06(02)$ & $15.12(09)$ & $12.54(02)$ & $14.23(07)$ \\
\hline 0.1 & $12.92(26)$ & $25.08(89)$ & $12.76(24)$ & $23.38(40)$ \\
\hline 0.2 & $12.90(32)$ & $28.63(28)$ & $12.44(26)$ & $27.48(30)$ \\
\hline 0.3 & $13.64(36)$ & $39.25(50)$ & $13.43(29)$ & $33.47(07)$ \\
\hline 0.4 & $13.23(38)$ & $46.74(30)$ & $13.01(34)$ & $40.49(99)$ \\
\hline 0.5 & $13.87(45)$ & $55.28(30)$ & $13.67(39)$ & $48.40(80)$ \\
\hline 0.6 & $13.77(41)$ & $69.47(75)$ & $13.57(38)$ & $57.47(60)$ \\
\hline 0.7 & $13.81(47)$ & $78.70(70)$ & $13.59(42)$ & $68.83(50)$ \\
\hline 0.8 & $13.56(45)$ & $85.20(48)$ & $13.29(45)$ & $72.60(44)$ \\
\hline 0.9 & $13.46(54)$ & $85.81(45)$ & $13.29(71)$ & $78.10(60)$ \\
\hline \multirow[t]{3}{*}{1} & $13.84(01)$ & $93.58(03)$ & $13.68(05)$ & $79.21(04)$ \\
\hline & \multicolumn{2}{|c|}{$308 \mathrm{~K}$} & \multicolumn{2}{|c|}{$318 \mathrm{~K}$} \\
\hline & $\varepsilon_{0}$ & $\tau$, ps & $\varepsilon_{0}$ & $\tau, \mathrm{ps}$ \\
\hline 0 & $11.86(01)$ & $13.50(05)$ & $10.75(01)$ & $11.72(07)$ \\
\hline 0.1 & $12.63(21)$ & $21.17(11)$ & $12.59(15)$ & $15.58(60)$ \\
\hline 0.2 & $12.41(23)$ & $24.13(10)$ & $12.20(28)$ & $18.00(70)$ \\
\hline 0.3 & $12.93(27)$ & $30.16(80)$ & $12.63(20)$ & $23.95(48)$ \\
\hline 0.4 & $12.76(28)$ & $35.01(60)$ & $12.16(22)$ & $27.94(41)$ \\
\hline 0.5 & $13.48(29)$ & $42.28(50)$ & $13.19(24)$ & $32.38(35)$ \\
\hline 0.6 & $13.12(31)$ & $50.39(40)$ & $13.03(22)$ & $37.61(24)$ \\
\hline 0.7 & $13.31(37)$ & $56.16(35)$ & $13.28(39)$ & $44.49(40)$ \\
\hline 0.8 & $13.28(48)$ & $60.99(42)$ & $13.14(30)$ & $48.74(25)$ \\
\hline 0.9 & $13.20(55)$ & $63.13(40)$ & $12.93(34)$ & $53.22(24)$ \\
\hline 1 & $13.44(06)$ & $67.20(04)$ & $13.17(05)$ & $58.95(03)$ \\
\hline
\end{tabular}


temperature, the relaxation time values are decreasing by maintaining the same type of variation with change in concentration. In the DP-rich region, $\tau$ values are not so much sensitive with change in temperature. The values $\varepsilon_{0}$ as well as $\tau$ increase with increase in volume fraction of DMAE in DP, which indicates that with increase in the number of dipoles in the solution, the intermediate structures formed rotate slowly thereby giving the increase in the values of $\tau$ in the solution.

A large value of $\tau$ for DMAE molecules is attributed to $\mathrm{H}$-bonded polymeric cluster formation. The primary relaxation of DMAE may be due to the cooperative process of long chain multimers with $(\mathrm{O}-\mathrm{H} \cdots \mathrm{N}$ or may be $\mathrm{H}-\mathrm{N} \cdots \mathrm{H})$ linkage. The observed relaxation time $\tau$ of DMAE (79.21 ps) is much smaller than the $\tau$ of ethanolamine (155 ps) [19] and ethanol (139.85 ps) [20], which suggests that there is substantial hindrance to molecular reorientation due to the bulky $-\mathrm{CH}_{3}$ side group in ethanol. Moreover, the fact that the $\tau$ values of amines are smaller than homologous alcohols indicates [21], on the one hand, the weaker dipolar character of the $\mathrm{NH}_{2}$ group with respect to the $\mathrm{OH}$ group and, on the other hand, that the relaxation times for amines are near to the rotation time of the $\mathrm{NH}_{2}$ group in its free state. The $\tau$ value of DMAE is much smaller than ethanol and aminoethanol, which suggests that there is substantial hindrance to molecular reorientation due to the terminal hydroxy $(\mathrm{OH})$ and dimethylamine $\left(-\mathrm{N}\left(\mathrm{CH}_{3}\right)_{2}\right)$ groups. The Kirkwood correlation factor of propylamine $(g=1.45)$ [22] is larger in comparison with DP $(g=1.003)$, the observed relaxation time $\tau$ of DP (14.23 ps) is much larger than the $\tau$ of propylamine (3.05 ps), which suggests the fact that there is substantial hindrance to molecular reorientation due to $-\mathrm{NH}_{2}$ groups and also bulky $-\mathrm{CH}_{3}$ side group of propane. Increase in volume fraction of DMAE in DP when relaxation value $\tau$ increases is a manifestation of the dielectric orientation of the clusters containing both DP and DMAE molecules, which is because of the continuous breaking and making of $\mathrm{H}$-bonds in the heterogeneous mixture.

The excess parameters $[22,23]$ related to $\varepsilon_{0}$ and $\tau$ provide valuable information regarding interaction between (solute-solvent) polar-polar liquid mixtures. These properties are also useful for the detection of the cooperative domain in the mixture and may give evidence for the formation of multimers in the mixture due to intermolecular interaction. The excess permittivity is defined as

$$
\left.\varepsilon^{\mathrm{E}}=\left(\varepsilon_{\mathrm{o}}\right)_{\mathrm{m}}-\left[\left(\varepsilon_{\mathrm{o}}\right)_{\mathrm{A}} x_{\mathrm{A}}+\left(\varepsilon_{\mathrm{o}}\right)_{\mathrm{B}} x_{\mathrm{B}}\right)\right],
$$

where $x$ is the mole fraction, and suffixes $\mathrm{m}, \mathrm{A}, \mathrm{B}$ represent mixture, liquid $\mathrm{A}$ and liquid $\mathrm{B}$, respectively.

The excess inverse relaxation time is defined as

$$
(1 / \tau)^{\mathrm{E}}=(1 / \tau)_{\mathrm{m}}-\left[(1 / \tau)_{\mathrm{A}} x_{\mathrm{A}}+(1 / \tau)_{\mathrm{B}} x_{\mathrm{B}}\right],
$$

which represents average broadening of dielectric spectra. The inverse relaxation time analogy is taken from spectral line broadening (which is the inverse of relaxation time) from the resonant spectroscopy [24].

In DP-DMAE, three kinds of cooperative domains are expected due to molecular interactions: $\mathrm{CO}^{-}$ operative domain (CD) includes DP molecules only, $\mathrm{CD}$ includes DMAE molecules only, and CD includes both DP and DMAE molecules. Further, the ratio of these cooperative domains may vary with concentration of individual molecules in the mixture. For the detection of the $\mathrm{CD}$ in the mixture, it is useful to compute the excess permittivity $\varepsilon^{\mathrm{E}}$ which may provide evidence for the formation of dimmers/multimers in the mixture due to molecular interactions.

The obtained excess permittivity and excess inverse relaxation data for the binary mixture of DP-DMAE are presented in Figs. 3 and 4, respectively. The observed $\varepsilon^{\mathrm{E}}$ is found to be negative at the DMAE-rich region for all temperatures and at the DP-rich region at $288 \mathrm{~K}$ (Fig. 3 ). The negative values of $\varepsilon^{\mathrm{E}}$ indicate that the total number of dipoles decreases in the DMAE- and DP-rich region (288 K) which is due to the opposite alignment of the dipoles of the interacting DP and DMAE molecules. Further, the low value of $\varepsilon^{\mathrm{E}}$ at concentrations near to that of pure DMAE indicates that there is less interaction between DP and DMAE molecules, and hence cooperative domain decreases in comparison with the cooperative domain including DP-DMAE molecules at remaining concentrations. The positive value of $\varepsilon^{\mathrm{E}}$ indicates that the total number of dipoles in DPDMAE increases with the formation of monomeric or dimeric structures which is due to the parallel alignments of the dipoles of the interacting DP and DMAE molecules. 


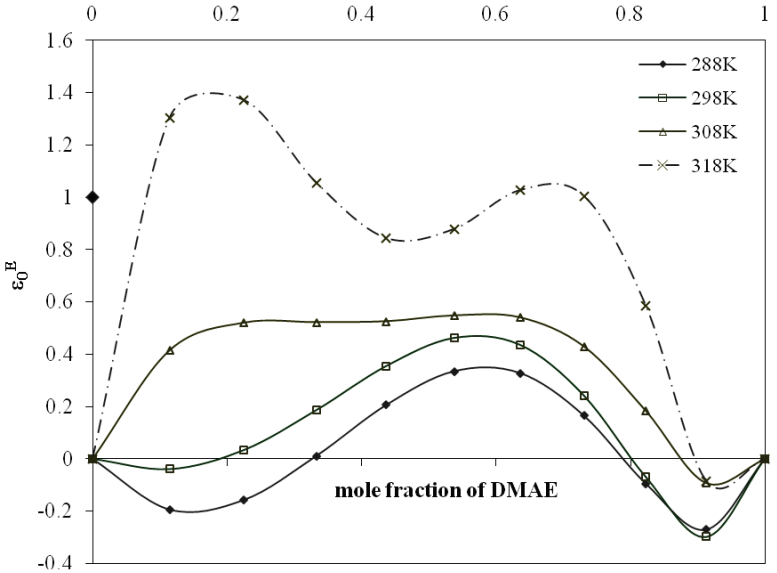

Fig. 3. Variation of excess permittivity with mole fraction of dimethylaminoethanol in 1,2-diaminopropane at various temperatures.

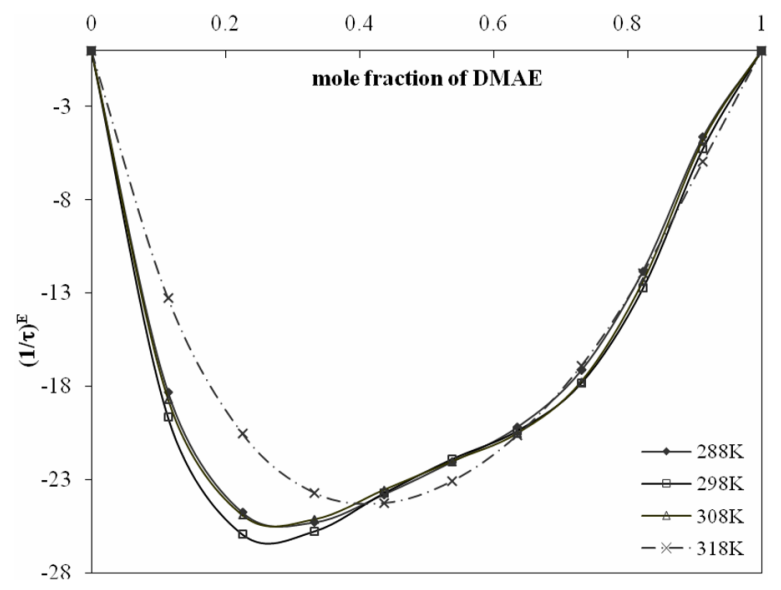

Fig. 4. Variation of excess inverse relaxation time with mole fraction of dimethylaminoethanol in 1,2-diaminopropane at various temperatures.

From Fig. 4 it is found that the $(1 / \tau)^{\mathrm{E}}$ values of DP-DMAE binary mixtures are negative over the entire concentration range. The negative peak value is observed at $80 \% \mathrm{DP}-\mathrm{DMAE}$ concentration. The negative values of $(1 / \tau)^{\mathrm{E}}$ indicate the formation of linear structures, probably dimeric, and these rotate slowly under the influence of an external varying field.

Different molecules are connected by hydrogen bonds; it will be necessary to break these bonds for the dielectric relaxation to be produced. This question has been envisaged by considering the Kirkwood correlation factor $g$ [25] which itself ex- presses the existing dipolar correlation between the molecule and its surroundings.

The $g$ for pure liquid can be obtained by the expression

$$
\frac{4 \pi \mathrm{N} \mu^{2} \rho}{9 k \mathrm{TM}} \mathrm{g}=\frac{\left(\varepsilon_{0}-\varepsilon_{\infty}\right)\left(2 \varepsilon_{0}+\varepsilon_{\infty}\right)}{\varepsilon_{0}\left(\varepsilon_{\infty}+2\right)^{2}}
$$

where $\mu$ is the dipole moment, $\rho$ is the density of liquid at temperature $T, M$ is the molecular weight, $k$ is the Boltzmann constant, and $N$ is the Avogadro's number.

The effective averaged angular Kirkwood correlation factor $g^{\text {eff }}[26,27]$ of the mixed solvents was determined by the following volume fractionweighted mixture law:

$$
\begin{aligned}
& \frac{4 \pi \mathrm{N}}{9 k \mathrm{~T}}\left(\frac{\mu_{\mathrm{A}}^{2} \rho_{\mathrm{A}}}{\mathrm{M}_{\mathrm{A}}} \Phi_{\mathrm{A}}+\frac{\mu_{\mathrm{B}}^{2} \rho_{\mathrm{B}}}{\mathrm{M}_{\mathrm{B}}} \Phi_{\mathrm{B}}\right) \mathrm{g}^{\text {eff }}= \\
& \frac{\left(\varepsilon_{0 \mathrm{~m}}-\varepsilon_{\infty \mathrm{m}}\right)\left(2 \varepsilon_{0 \mathrm{~m}}+\varepsilon_{\infty \mathrm{m}}\right)}{\varepsilon_{0 \mathrm{~m}}\left(\varepsilon_{\infty \mathrm{m}}+2\right)^{2}}
\end{aligned}
$$

where $g^{\text {eff }}$ is the effective Kirkwood correlation factor for a binary mixture, and $\Phi_{A}$, $\Phi_{B}$ are volume fraction of liquid $A$ and liquid $B$, respectively.

Considering the Kirkwood correlation factors $g_{1}$ and $g_{2}$ for the molecules of liquids 1 and 2 which contributed proportional to their pure liquid $g$ values in the binary mixture, Eq. (7) of the Kirkwood correlation factor can be written as

$$
\begin{aligned}
& \frac{4 \pi \mathrm{N}}{9 k \mathrm{~T}}\left(\frac{\mu_{\mathrm{A}}^{2} \rho_{\mathrm{A}} g_{A}}{\mathrm{M}_{\mathrm{A}}} \Phi_{\mathrm{A}}+\frac{\mu_{\mathrm{B}}^{2} \rho_{\mathrm{B}} g_{B}}{\mathrm{M}_{\mathrm{B}}} \Phi_{\mathrm{B}}\right) \mathrm{g}_{\mathrm{f}}= \\
& \frac{\left(\varepsilon_{0 \mathrm{~m}}-\varepsilon_{\infty \mathrm{m}}\right)\left(2 \varepsilon_{0 \mathrm{~m}}+\varepsilon_{\infty \mathrm{m}}\right)}{\varepsilon_{0 \mathrm{~m}}\left(\varepsilon_{\infty \mathrm{m}}+2\right)^{2}},
\end{aligned}
$$

where $g_{\mathrm{f}}$ is the corrective Kirkwood correlation factor for a binary mixture. The evaluated $g_{\mathrm{f}}$ values of the DP-DMAE mixture are given in Fig. 5.

The calculated values of $g^{\text {eff }}$ are presented in Table 2 . The $g^{\text {eff }}$ values change periodically with change in concentration of DMAE in binary mixture of DP-DMAE. This concentration-dependent periodic behaviour of the investigated mixed solvents 


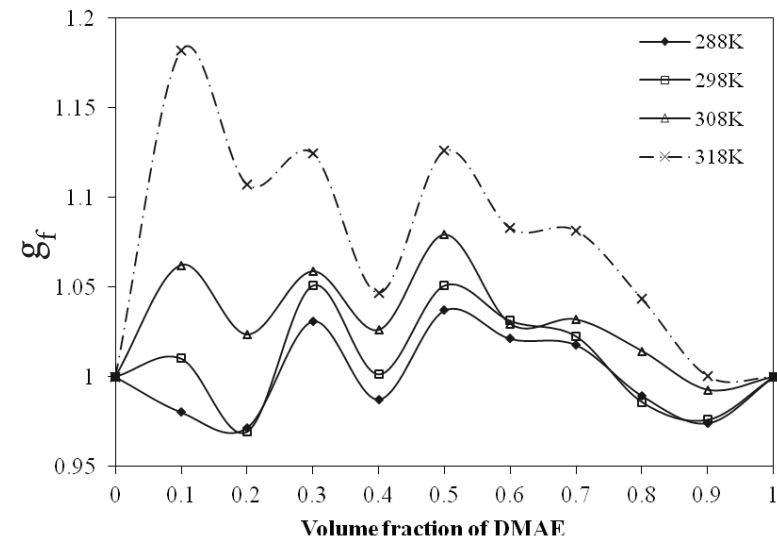

Fig. 5. Plots of $g_{\mathrm{f}}$ against volume fraction of dimethylaminoethanol for 1,2-diaminopropane-dimethylaminoethanol binary mixtures at various temperatures.

confirms the change in dipolar ordering of DMAE molecules due to their $\mathrm{H}$-bond molecular interactions with DP molecules. The corrective Kirkwood correlation factor $g_{\mathrm{f}}$ of the investigated mixtures deviate from unity (Fig. 5) confirming the change in net dipolar ordering. The plots of $g_{\mathrm{f}}$ values of DP-DMAE mixtures have good resemblance with their corresponding $\varepsilon^{\mathrm{E}}$ plots, i. e. the mixtures which have $g_{f}$ values greater than unity have positive $\varepsilon^{\mathrm{E}}$ values, and vice versa (Fig. 3 ). The $g_{\mathrm{f}}$ values higher than unity for DP-DMAE mixtures reveal enhanced in the effective dipolar ordering due to hetero-molecular H-bond interactions. Whereas the $g_{\mathrm{f}}$ values of DMAE and DP $(288 \mathrm{~K})$ rich region

Table 2. The value of Kirkwood correlation factor $\left(g^{\text {eff }}\right)$ for dimethylaminoethanol-1,2-diaminopropane binary mixture at various temperatures.

\begin{tabular}{lllll}
\hline \multirow{2}{*}{$\mathrm{X}_{\text {DMAE }}$} & \multicolumn{4}{c}{$g^{\text {eff }}$} \\
\cline { 2 - 5 } & $288 \mathrm{~K}$ & $298 \mathrm{~K}$ & $308 \mathrm{~K}$ & $318 \mathrm{~K}$ \\
\hline 0 & 1.02 & 1.00 & 0.97 & 0.88 \\
\hline 0.1 & 0.99 & 1.01 & 1.03 & 1.06 \\
\hline 0.2 & 0.98 & 0.97 & 1.00 & 1.01 \\
\hline 0.3 & 1.04 & 1.05 & 1.04 & 1.04 \\
\hline 0.4 & 0.99 & 1.00 & 1.01 & 0.99 \\
\hline 0.5 & 1.03 & 1.05 & 1.07 & 1.08 \\
\hline 0.6 & 1.01 & 1.03 & 1.02 & 1.05 \\
\hline 0.7 & 1.01 & 1.02 & 1.03 & 1.06 \\
\hline 0.8 & 0.98 & 0.99 & 1.02 & 1.04 \\
\hline 0.9 & 0.96 & 0.98 & 1.00 & 1.01 \\
\hline 1 & 0.98 & 1.00 & 1.01 & 1.02 \\
\hline
\end{tabular}

are less than unity, which suggests that the addition of a small amount of DMAE breaks a large amount of $\mathrm{H}$-bonded long-range ordered DP structures.

Since the Arrhenius plots of $\log \tau$ vs $1 / T$ displayed a good linearity for all the studied liquid mixtures, the kinetic parameters that characterise the molecular mobility in those systems were evaluated using the Eyring formula [28, 29].

The dielectric relaxation can be treated as a rate process involving a path over a potential barrier [24, 29]. Figure $6(a, b)$ shows free energy of activation $\Delta G$ of the DP-DMAE mixtures as a function of temperature at different solution compositions and as a function of solution composition at different temperatures, respectively. Over the temperature range of $288-318 \mathrm{~K}, \Delta G$ varies gradually with the mole fraction of DMAE. It is observed that the $\Delta G$ values of DMAE are higher than those of DP over the temperature range of $288-318 \mathrm{~K}$. This difference is attributed to the formation of hydrogen bonded networks for DP and DMAE that tend to increase the effective size of a rotating dipole and the dielectric frictional force between the rotating dipole and its neighbouring molecules. Despite the distinctly different $\Delta G$ values of DP and DMAE and the presence of hydrogen bonding between DP and DMAE molecules, there is a gradual increase in $\Delta G$ with increase in DMAE composition as shown in Fig. 6(b), which

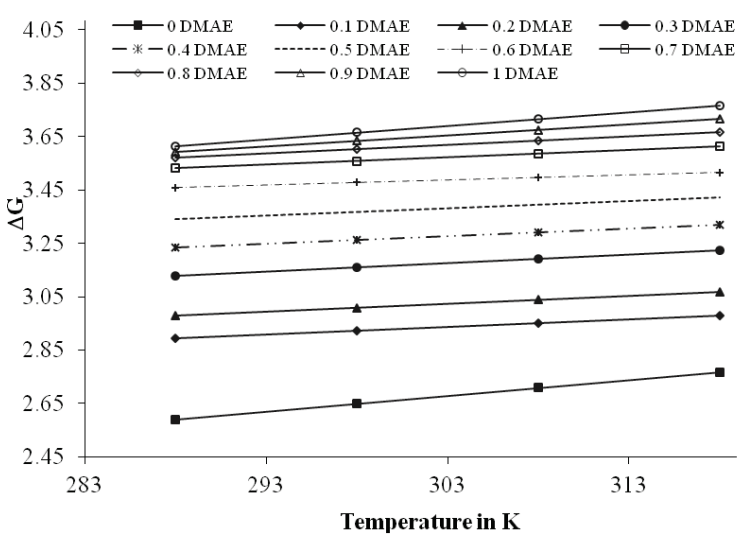

Fig. 6(a). Variation of free energy of activation $\Delta G$ for the dipolar relaxation for dimethylaminoethanol-1, 2-diaminopropane binary mixture as a function of temperature. 


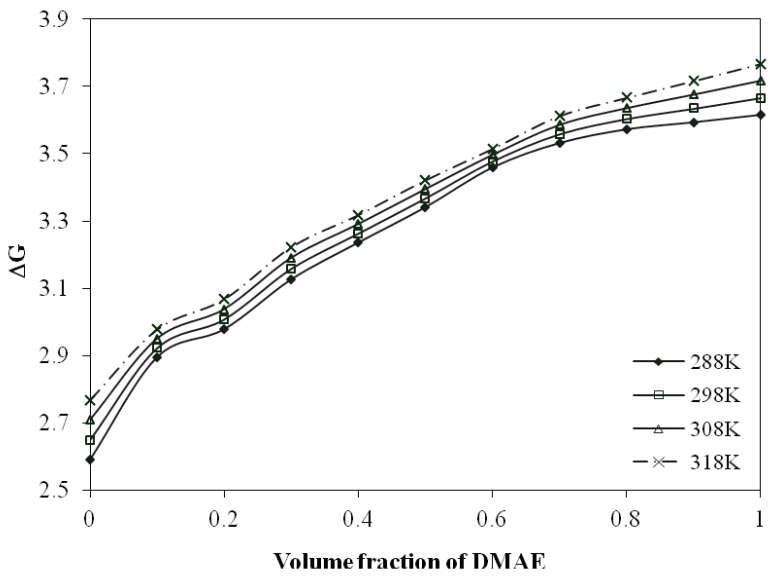

Fig. 6(b). Variation of free energy of activation $\Delta G$ for the dipolar relaxation for dimethylaminoethanol-1, 2-diaminopropane binary mixture as a function of solution composition.

suggests that the DP and DMAE molecules in the mixture react to the external field in a strongly cooperative way rather than individually over the temperature range of $288-318 \mathrm{~K}$. It also suggests that there is more hindrance to the rotation of the $\mathrm{DP}$ and DMAE molecule clusters in DP-DMAE in comparison with the rotation of their homogeneous clusters. This also supports the conclusions drawn from the negative values of the excess inverse relaxation time. Further, the increase in hindrance to molecular rotation in the mixture is due to intermolecular interactions between the DP and DMAE molecules, and hence chain-like structures are generated in DP-DMAE, which supports the excess permittivity and relaxation time data. In the DP-DMAE mixtures, the two different molecules are suggested to behave interchangeably in forming the cyclic molecular clusters, yielding a microscopically homogeneous liquid phase and a pure Debye-type dielectric dispersion. The primary relaxation in these mixtures is attributed to the cooperative process of the cyclic clusters, with the clusters having an increased dipole moment relative to the individual molecules. Figure 6(a) shows that $\Delta G$ of DP-DMAE mixtures is a linear function of temperature over the range of $288-318 \mathrm{~K}$. The varying relaxation behaviour over the entire temperature range may be caused by changes in the hydrogen-bonding ability that produce different structures of chain-like or cyclic clusters.
Factors such as changes in the angle between the neighbouring dipoles or in the average number of molecules in each cluster could yield different cluster structures. Tsurko et al. [30] reported the activation energy for the amino acid-propanol binary mixture. They suggested that the activation energy increased with increase in mole fraction of propanol and temperature. Jianfeng Lou et al. [31] reported $\Delta G$ for the nitrobenzene-toluene, ethanol-butanol and butanol-formamide. They suggested that $\Delta G$ for nitrobenzene-toluene mixture linearly increases with increase in mole fraction of nitrobenzene and temperature, consistent with the ideal dielectric mixing behaviour that might be expected on the basis of the nature of these solvent mixtures. Nitrobenzene and toluene are polar and non-polar solvents, respectively, and they do not associate with each other or with like molecules. But in case of ethanol-butanol and butanolformamide, $\Delta G$ linearly increases with increase in compositions but decreases with increase in temperature. This may be due to the molecules in both mixtures reacting to the external field in a strongly cooperative way.

An interesting trend may be observed in the temperature-dependent relaxation time for the DP-DMAE binary mixture. The most probable relaxation time determined for the DP-DMAE binary mixture decreases with increasing temperature. In general, this type of temperature-dependent effect could indicate either a temperature-dependent rate process with activation energy or an equilibrium process with an enthalpy change between the two (or perhaps more) states $(\Delta H)$.

The value of $\Delta H$ increases with increase in volume fraction of DMAE in DP from $3.72 \mathrm{~kJ} /$ $(\mathrm{K} \cdot \mathrm{mol})$ to $12.23 \mathrm{~kJ} /(\mathrm{K} \cdot \mathrm{mol})$ with increase in volume fraction of DMAE up to 0.6 in the mixture of DP-DMAE (Table 3). This indicates that more energy is needed for group dipole reorientation with increase in volume fraction of DMAE in the mixture. There is an increase in agitation with increase in volume fraction of DMAE up to $60 \%$ in the mixture, which may be due to the interaction in $\mathrm{NH}_{2}-\mathrm{NH}_{2}$ group or may be due to $\mathrm{NH}_{2}-$ $\mathrm{OH}$ group. Furthermore, $\Delta H$ decreases towards the corresponding $\Delta H$ value of pure DMAE. A large value of $\Delta H$ at 0.6 volume fraction of DMAE indicates strong hydrogen bonding in the solution. 
Table 3. The activation enthalpy $(\Delta H)$ of dimethylaminoethanol-1,2-diaminopropane binary mixture for various concentrations.

\begin{tabular}{c|c}
\hline $\mathrm{X}_{\text {DMAE }}$ & $\begin{array}{c}\text { Activation enthalpy } \Delta H, \\
\mathrm{~kJ} /(\mathrm{K} \cdot \mathrm{mol})\end{array}$ \\
\hline 0 & 3.72 \\
\hline 0.1 & 8.81 \\
\hline 0.2 & 8.86 \\
\hline 0.3 & 9.22 \\
\hline 0.4 & 10.23 \\
\hline 0.5 & 10.75 \\
\hline 0.6 & 12.23 \\
\hline 0.7 & 11.53 \\
\hline 0.8 & 11.17 \\
\hline 0.9 & 10.08 \\
\hline 1 & 9.02 \\
\hline
\end{tabular}

\section{Conclusions}

The dielectric dispersion $\varepsilon^{\prime}$ and dielectric loss $\varepsilon^{\prime \prime}$ of binary mixture of 1,2-diaminopropane in dimethylaminoethanol have been studied using the TDR technique in the frequency range from $10 \mathrm{MHz}$ to $20 \mathrm{GHz}$ over entire concentration at $288,298,308$, and $318 \mathrm{~K}$. Both $\varepsilon^{\prime}$ and $\varepsilon^{\prime \prime}$ increase with increase in volume percentage of DMAE in DP-DMAE mixture at the low-frequency end and decrease at the high-frequency end. The $\varepsilon_{0}$ as well as $\tau$ values increase with increase in volume fraction of DMAE in DP, which indicates that with increase in the number of dipoles in the solution the intermediate structures formed rotate slowly thereby giving the increase in the values of $\tau$ in the solution. The plots of $g_{\mathrm{f}}$ values of DP-DMAE mixtures have good resemblance with their corresponding $\varepsilon^{\mathrm{E}}$ plots, i. e. the mixtures which have $g_{\mathrm{f}}$ values greater than unity, have positive $\varepsilon^{\mathrm{E}}$ values, and vice versa. The $g_{\mathrm{f}}$ values higher than unity for DP-DMAE mixtures reveal enhancement in the effective dipolar ordering due to hetero-molecular $\mathrm{H}$-bond interactions. The dielectric behavior of 1,2-diaminopropane and dimethylaminoethanol liquid molecules and their conformations as well as molecular dynamics of the system can be explored only by comparing the dielectric data of the mixture system with the dielectric data of the individual molecules and their dynamics.

\section{References}

[1] C. Gabriel, S. Gabriel, E.H. Grant, B.S.J. Halstead, and D.M.P. Mingos, Chem. Soc. Rev. 27, 213 (1998).

[2] W. Kuang, and S.O. Nelson, J. Microw. Power Electromagn. Energ. 32, 114 (1997).

[3] U. Becker and M. Stockhausen, J. Mol. Liq. 81, 89 (1999).

[4] R.J. Sengawa, R. Chaudhary, and S.C. Mehrotra, Polymer 43, 1467 (2002).

[5] S.M. Puranik, A.C. Kumbharkhane, and S.C. Mehrotra, Indian J. Phys. 67(B), 9 (1993).

[6] F.F. Hanna, Bo Gestblom, and A. Soliman, J. Mol. Liq. 95, 27 (2000).

[7] M.J.C. van Gemert, Adv. Mol. Relaxation Processes 6, 123 (1974).

[8] D. Bertolini, M. Cassettari, S. Salvetti, E. Tombari, and S. Veronesi, Rev. Sci. Instrum. 61, 2416 (1990).

[9] J.G. Berberian and E. King, J. Non-Cryst. Solids. 305, 10 (2002).

[10]C.E. Shannon, Proc. Inst. Radio Eng. 37, 10 (1949).

[11]H.A. Samulan, Proc. Inst. Radio Eng. 39, 175 (1951).

[12] S. Mashimo, S. Kuwabara, S. Yogihara, and K. Higasi, J. Chem. Phys. 90, 3292 (1989).

[13] R.H.Cole, J.G. Berbarian, S.G. Chryssikos, A. Burns, and E. Tombari, J. Appl. Phys. 66, 793 (1989).

[14] S. Havriliak and S. Negami, J. Polymer. Sci. C 14, 99 (1966).

[15]K.S. Cole and R.H. Cole, J. Chem. Phys. 9, 341 (1941).

[16] D.W. Davidson and R.H. Cole, J. Chem. Phys. 18, 1484 (1950).

[17] P. Debye, Polar Molecules The Chemical Catalogue Co., New York, 1929).

[18] S. Kumar, T. Ganesh, S. Krishana, and S.C. Mehrotra, Bull. Pure Appl. Sci. D 20(1), 125 (2001).

[19] P. Undre, S.N. Helambe, S.B. Jagdale, P.W. Khirade, and S.C. Mehrotra, J. Mol. Liq. 137, 147 (2008).

[20] B.G. Lone, P.B. Undre, S.S. Patil, P.W. Khirade, and S.C. Mehrotra, J. Mol. Liq. 141, 47 (2008).

[21] A. Volmari and H. Weingartner, J. Mol. Liq. 98-99, 293 (2002).

[22] F.J. Arcega, J.M. Fornies-Marquina, A.M. Bottreau, and G. Vicq, An. Fys. 77 B, 28 (1981).

[23] M. Tabellout, P. Lanceleur, J.R. Emery, D.Hayward, and R.A. Pethrick, J. Chem. Soc. Farad. and Trans. 86, 1493 (1990).

[24] J. Lou, T.A. Hatton, and P.E. Laibinis, J. Phys. Chem. A 101, 5262 (1997).

[25] G. Oster and J.G. Kirkwood, J. Chem. Phys. 11, 175 (1943).

[26] A.C. Kumbharkhane, S.M. Puranik, and S.C. Mehrotra, J. Solution Chem. 22, 219 (1993).

[27] G. MouMouzlas, D.K. Panpoulos, and G. Ritzoulis, J. Chem. Eng. Data 36, 20 (1991). 
[28] N.E. Hill, W. Vaughan, A.H. Price, and M. Davies, Dielectric Properties and Molecular Behaviour (Van Nostrand Reinhold Co., London, 1969).

[29] S. Glasstone, K.J. Laidler, and H. Eyring, The Theory of Rate Processes (McGraw-Hill Book Co., New York, 1941).
[30]E.N. Tsurko, T.M. Shihova, and N.V. Bondarev, J. Mol. Liqs. 96-97, 425 (2002).

[31]J.Lou,A.K.Paravastu, P.E.Laibinis, and T.A.Hatton, J. Phys. Chem. A 101, 9892 (1997).

\title{
DIELEKTRINĖ DISPERSIJA 1,2-DIAMINOPROPANO IR DIMETILAMINOETANOLIO MIŠINIUOSE, PRIKLAUSANTI NUO SUDĖTIES IR TEMPERATÜROS
}

\author{
P. Undre, P. W. Khirade \\ Babasaheb Ambedkar Marathwada universiteto Fizikos katedra, Aurangabadas, Indija
}

\begin{abstract}
Santrauka
Dielektrinè dispersija $\varepsilon^{\prime}$ ir dielektriniai nuostoliai $\varepsilon^{\prime \prime}$ dvinariuose 1,2-diaminopropano ir dimetilaminoetanolio mišiniuose matuoti laikinès reflektometrijos metodu $10 \mathrm{MHz}-20 \mathrm{GHz}$ dažnių ruože, esant 288, 298,308 ir $318 \mathrm{~K}$ temperatūrai. Šiuo metodu matuojant $\varepsilon^{\prime}$ ir $\varepsilon^{\prime \prime}$ vertes matavimo paklaida yra ne didesnè nei $\pm 5 \%$. Siekiant ịvertinti įvairius dielektrinius parametrus, nuo laiko priklausančios kompleksinès skvarbos $\left(\varepsilon^{*}(\omega)=\varepsilon^{\prime}-\mathrm{i} \varepsilon^{\prime \prime}\right)$ duomenys, pavyzdžiui, statinè dielektrinè skvarba $\left(\varepsilon_{0}\right)$, relaksacijos trukmè $(\tau)$ ir skvarba esant aukštam dažniui $\left(\varepsilon_{\infty}\right)$, netiesiniu
\end{abstract}

mažiausių kvadratų metodu aproksimuoti Debajaus formule. Iš nustatytų $\varepsilon_{0}, \tau$, Kirkvudo (Kirkwood) koreliacijos daugiklio $(g)$, aktyvacijos laisvosios energijos $(\Delta \mathrm{G})$ ir aktyvacijos entalpijos $(\Delta \mathrm{H})$ temperatūriu priklausomybių daromos išvados apie $-\mathrm{NH}_{2}$ ir $-\mathrm{CH}_{3}$ šoniniu grupių itaką molekulinei dinamikai ir tarpmolekuliniams vandeniliniams ryšiams. 1,2-diaminopropano ir dimetilaminoetanolio skysčių molekulių ir jų konformacijų dielektrinès savybès bei molekulių dinamika gali būti ištirtos tik palyginus dielektrinius mišinio sistemos duomenis su pavienių molekulių ir jų dinamikos dielektriniais duomenimis. 